\title{
Active Contribution of Dendrites to the Tonic and Trimodal Patterns of Activity in Cerebellar Purkinje Neurons
}

\author{
Mary Womack and Kamran Khodakhah \\ Department of Physiology and Biophysics, University of Colorado Health Sciences Center, Denver, Colorado 80262, and \\ Department of Neuroscience, Albert Einstein College of Medicine, Bronx, New York 10461
}

The cerebellum is responsible for coordination of movement and maintenance of balance. Cerebellar architecture is based on repeats of an anatomically well defined circuit. At the center of these functional circuits are Purkinje neurons, which form the sole output of the cerebellar cortex. It is proposed that coordination of movement is achieved by encoding timing signals in the rate of firing and pattern of activity of Purkinje cells. An understanding of cerebellar timing requires an appreciation of the intrinsic firing behavior of Purkinje cells and the extent to which their activity is regulated within the functional circuits. We have examined the spontaneous firing of Purkinje neurons in isolation from the rest of the cerebellar circuitry by blocking fast synaptic transmission in acutely prepared cerebellar slices. We find that, intrinsically, mature Purkinje cells show a complex pattern of activity in which they continuously cycle among tonically firing, bursting, and silent modes. This trimodal pattern of activity emerges as the cerebellum matures anatomically and functionally. Concurrent with the transformation of the immature tonically firing cells to those with the trimodal pattern of activity, the dendrites assume a prominent role in regulating the excitability of Purkinje cells. Thus, alterations in the rate and pattern of activity of Purkinje neurons are not solely the result of synaptic input but also arise as a consequence of the intrinsic properties of the cells.

Key words: cerebellum; calcium channels; excitability; intrinsic firing; motor coordination; activity pattern
The cerebellum is the structure bestowed primarily with the function of motor coordination, a task achieved by the generation of precise timing signals for augmentation and inhibition of the appropriate agonist and antagonist muscles. Cerebellar timing signals are thought to be encoded by transient changes in the rate of firing of Purkinje neurons, cells that constitute the sole output of the cerebellar cortex (Ito, 1984). Purkinje cells are the principal neurons of anatomically well defined circuits. Their extensive dendritic tree allows them, in principle, to integrate their vast excitatory and inhibitory synaptic inputs and to relay the outcome to their targets in the deep cerebellar nuclei. Recordings in cerebellar slices (Llinas and Sugimori, 1980a,b; Chang et al., 1993; Jaeger and Bower, 1994; Hausser and Clark, 1997; Jaeger and Bower, 1999) and in vivo (Granit and Phillips, 1956; Eccles et al., 1966; Thach, 1967; Latham and Paul, 1971; Armstrong and Rawson, 1979; Jaeger and Bower, 1994) find that Purkinje cells fire tonically with occasional periods of burst firing and silence. To understand the function of the cerebellar timing circuits and their role in motor coordination, it is important to delineate the properties of each component of the circuit in isolation. Purkinje cells are intrinsically active and fire action potentials in the absence of excitatory synaptic input (Hausser and Clark, 1997; Nam and Hockberger, 1997; Raman and Bean, 1997; Jaeger and Bower, 1999). Although some researchers report that in the absence of synaptic input, Purkinje neurons fire at a fixed rate

\footnotetext{
Received March 26, 2002; revised Sept. 20, 2002; accepted Sept. 30, 2002.

This work was supported by a grant from the Whitehall Foundation. We thank Linda Hansen for managing the mouse colony and Dr. Margaret Neville for support. We also thank Drs. Donald Faber, Peter Sterling, Lawrence Cohen, and Nevin Lambert for discussion.

Correspondence should be addressed to Kamran Khodakhah, Department of Neuroscience, Albert Einstein College of Medicine, 506 Kennedy Center, 1410 Pelham Parkway South, Bronx, NY 10461. E-mail: kkhodakh@aecom.yu.edu. Copyright (C) 2002 Society for Neuroscience $\quad 0270-6474 / 02 / 2210603-\bullet 15.00 / 0$
}

(Hausser and Clark, 1997; Nam and Hockberger, 1997; Raman and Bean, 1997), others have observed more complex firing patterns (Jaeger and Bower, 1999). We have revisited this question by studying the firing pattern of Purkinje neurons in cerebellar slices under conditions in which fast excitatory and inhibitory synaptic inputs were blocked. We find that as the cerebellum matures, Purkinje cells change their intrinsic firing pattern from steady tonic firing to one in which they continuously switch among tonically firing, bursting, and silent modes. Furthermore, evidence is provided to show that dendrites make a significant contribution to the spontaneous firing.

\section{MATERIALS AND METHODS}

Preparation of slices. CD1 mice at $10 \mathrm{~d}$ to 3 months postnatally were anesthetized with halothane and decapitated. Three hundredmicrometer-thick sagittal slices were prepared from the vermis of the cerebellum using a vibratome (Campden Instruments). Slices were maintained at room temperature in the recording solution until use (1-8 hr).

Recording and analysis. Slices were mounted in a chamber on the stage of an upright microscope (Axioscope; Zeiss, Thornwood, NY) and visualized using a 40 or $63 \times$ water immersion objective with infrared optics. Slices were continuously superfused at a rate of $1.5 \mathrm{ml} / \mathrm{min}$ with recording solution of (in $\mathrm{mM}$ ): $\mathrm{NaCl}, 125 ; \mathrm{KCl}, 2.5 ; \mathrm{NaHCO}_{3}, 26$; $\mathrm{NaH}_{2} \mathrm{PO}_{4}, 1.25 ; \mathrm{MgCl}_{2}, 1 ; \mathrm{CaCl}_{2}, 2$; and glucose, $10, \mathrm{pH}$ 7.4, gassed with $5 \% \mathrm{CO}_{2}$ and $95 \% \mathrm{O}_{2}$. Where indicated, the recording solution also contained kynurenic acid $(5 \mathrm{mM})$ and picrotoxin $(200 \mu \mathrm{M})$. The slice temperature was maintained at $35 \pm 1^{\circ} \mathrm{C}$ by adjusting the temperature of the bathing solution. The volume of the chamber was $0.2 \mathrm{ml}$, requiring several minutes for complete wash-in of the antagonists or blockers. For local perfusion, a glass pipette connected to a reservoir containing perfusate was positioned just above the surface of the slice. Fast green $(0.4 \%)$ or phenol red $(0.4 \%)$ was included in the perfusate to monitor the location of the perfusate. At these concentrations, neither of the dyes makes a change in the firing of Purkinje neurons. A suction pipette was placed downstream from the perfusion pipette to limit the spread of the perfusate. The extent to which the perfusion was truly localized was assessed by monitoring the DC offset recorded by the differential amplifier when the perfusate was devoid of any ions (isotonic sucrose). Given 
Figure 1. Purkinje neurons exhibit a complex spontaneous firing pattern. $a$, Electrical activity of visually identified Purkinje neurons was monitored with extracellular field potential recording. Each action potential was registered as a rapid, negative voltage spike, which was often followed by a positive phase (right trace). $b$, Firing rate of a tonically firing Purkinje neuron. The cell fired at a relatively fixed rate of $50 \mathrm{spikes} / \mathrm{sec}$. No bursting behavior or long silent periods were observed. $c$, Firing rate of a Purkinje neuron that exhibited the trimodal firing pattern. The pattern consisted of a period of tonic firing, usually with a steady increase in rate, followed by a period of bursting and then a silent period lasting $\sim 20 \mathrm{sec} . d$, The pattern appears after block of rapid synaptic input. The average firing rate from a Purkinje neuron that fired at $\sim 50$ spikes/sec in the absence of pharmacological agents is shown. When fast excitatory and inhibitory synaptic transmissions were blocked, the tonic firing of the cell transformed into a trimodal pattern of activity. $e$, Average firing rate from a Purkinje neuron that exhibited the trimodal pattern in the absence of synaptic blockers. In the presence of synaptic blockers, the single-cycle duration of the pattern became somewhat shorter, and the firing rate during the tonically firing period became less variable. $f$, Average firing rate of a Purkinje neuron that maintained the trimodal pattern for $2 \mathrm{hr}$. The neuron fired throughout the $2 \mathrm{hr}$ recording with little variation in the average firing rate or in the single-cycle duration of the pattern. The recording was made in the continuous presence of kynurenate and picrotoxin.

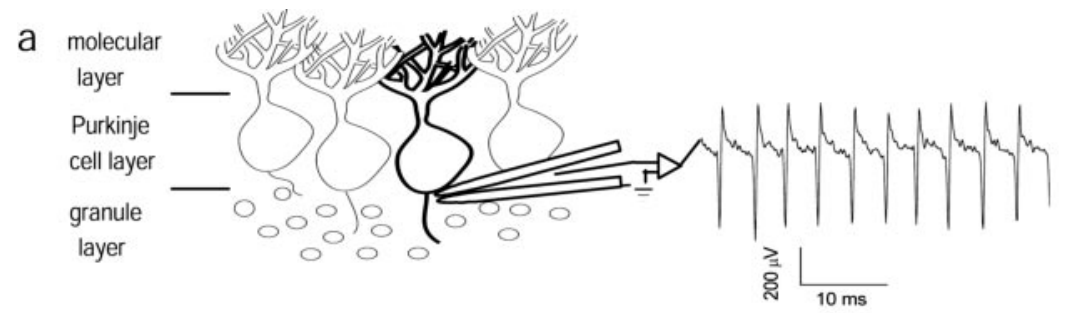

b

C

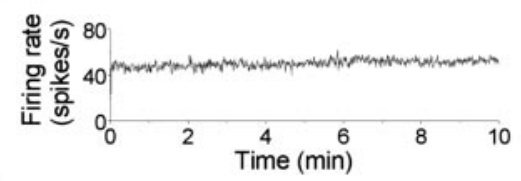

d
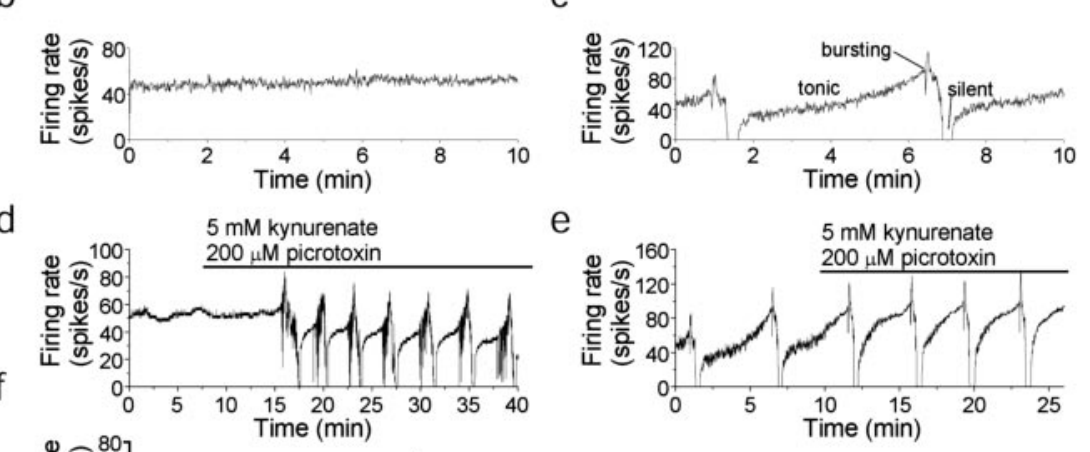

e
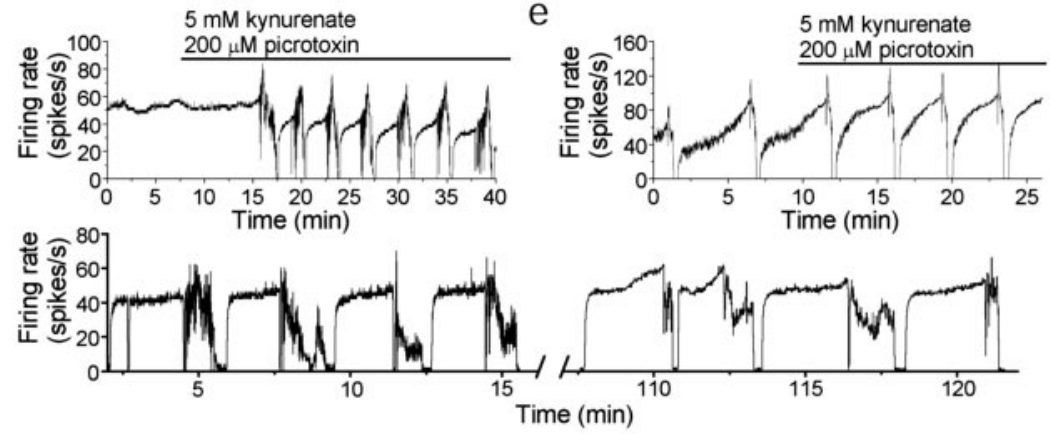

our experimental setup and the position of perfusion and suction pipettes, the visible dye front was determined to be a reliable measure of the extent of localized perfusion. Extracellular field potential recordings were made from individual Purkinje neurons using a homemade differential amplifier with glass pipette electrodes (tip size, $0.3-1 \mu \mathrm{m}$ ) filled with the recording solution. Data were sampled at $10 \mathrm{kHz}$ using a National Instruments (Austin, TX) MIO-16XE-10 digital-to-analoganalog-to-digital card and an IBM-compatible computer. Data acquisition and analyses were done with software written in-house using LabView (National Instruments). The pipette tip was positioned just above, or lightly touching, the cell body near the axon hillock where the largest potential changes were usually recorded. Action potentials appeared as fast negative deflections of $50-1000 \mu \mathrm{V}$. To analyze the firing rate, a threshold level for spike detection was set by eye during the experiment. The number of spikes crossing the threshold was counted every $500 \mathrm{msec}$ and is reported as the firing rate in terms of spikes per second. Data are reported as mean \pm SEM. Kynurenic acid, picrotoxin, and fast green were obtained from Sigma (St. Louis, MO); $\omega$-conotoxin MVIIC was from Bachem (Torrance, CA); 4-ethylphenylamino-1,2-dimethyl-6methylaminopyrimidinium chloride (ZD7288) and $N$-phenyl-7(hydroxyimino)cyclopropa(b)chromen-1a-carboxamide (PHCCC) were from Tocris Cookson (Ballwin, MO). All other chemicals were of reagent grade.

\section{RESULTS}

\section{Cerebellar Purkinje neurons exhibit an intrinsic firing pattern}

In the absence of any pharmacological manipulations, Purkinje cells taken from 10- to 20-d-old animals were spontaneously active, and most (10 of 15) fired tonically (Fig. 1b). With the exception of one cell, which burst at random, each of the remaining cells exhibited three different modes of activity. In these cells, the rate of tonic firing progressively increased until the cell started to burst (Fig. 1c). The bursting period was then followed by a period of inactivity. After this brief period of inactivity, the cell resumed firing, and the same transition from tonically firing to bursting activity to inactivity continuously repeated itself. This pattern of activity will hereafter be referred to as the "trimodal" pattern of activity.
To test whether the switch in the activity of the cell was synaptically driven, fast excitatory and inhibitory inputs were pharmacologically blocked. To block glutamate receptors, we used a wide-spectrum glutamate ionotropic receptor antagonist, kynurenic acid (5 mM; Stone, 1993). GABA ion channels were blocked with $200 \mu \mathrm{M}$ picrotoxin (Yoon et al., 1993). Pharmacological blockade of fast synaptic transmission not only did not abolish the trimodal pattern of activity in the four cells that had a pattern but also made it more regular (Fig. 1e). Moreover, blockade of synaptic transmission unmasked a trimodal pattern of activity in 3 of the 10 tonically firing neurons (Fig. $1 d$ ), and in the one cell that burst at random in the absence of antagonists (data not shown). In the tonically firing cells, the pattern took several minutes to emerge after superfusion with the antagonists (Fig. 1d). The remainder of tonically firing cells continued to fire steadily in the presence of the antagonists for as long as the recording was continued (20 min to several hours) without any bursts or pauses in the firing (Fig. 1f).

To characterize the properties of the trimodal pattern, further experiments were performed on an additional 202 cells, which were continuously superfused with kynurenic acid and picrotoxin. Nearly all the cells tested either fired tonically or exhibited the trimodal pattern. Thus, 89 of 202 cells fired tonically in the presence of the antagonists at a relatively fixed rate ranging from 10 to 135 spikes/sec (mean, $60 \pm 5$ spikes/sec; but also see Fig. $3 c$ ).

More than half of the cells $(n=108)$ had a trimodal pattern of activity. In these cells, the transition between the three modes followed a precise order and remained the same for as long as it was monitored (up to $5 \mathrm{hr}$ ). As can be seen in Figure 2, within a cycle each cell began to fire tonically, and monotonically increased its firing rate (Fig. $2 b, S$ ), until it eventually reached a transitional phase $(T)$ at which point it began to fire in bursts $(B)$. During the burst mode, the interburst intervals increased until the cell ceased firing. A new cycle of the trimodal pattern began 
a

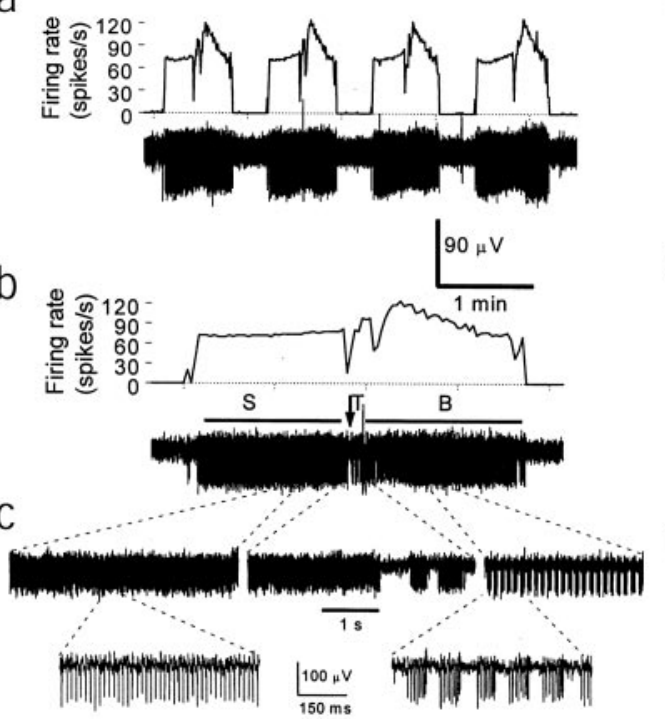

d

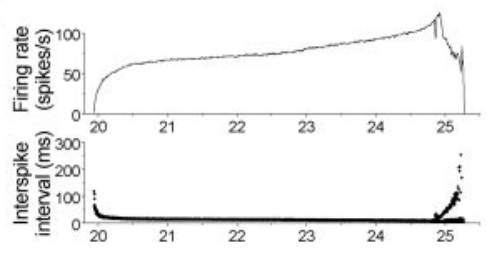

e

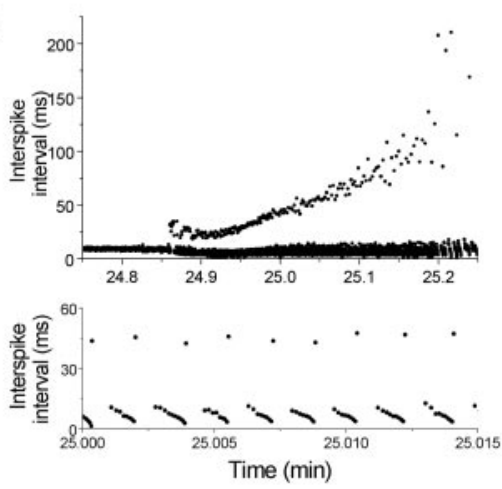

Figure 2. Cells with the trimodal pattern of activity regularly cycle among tonic, burst, and silent modes. $a$, Four cycles of the pattern are shown in a cell with the trimodal pattern of activity. The average firing rate is plotted in the top trace, whereas the bottom trace shows the corresponding field potential recording. Each pattern concludes with a silent mode. $b$, Recording from the same neuron on an expanded time scale. The trimodal pattern of activity consists of a duration of tonic firing $(S)$ with a gradual increase in firing rate. The tonic firing mode ends at a transitional time $(T)$ when the cell begins bursting. The burst durations and interburst intervals are initially erratic and then become very regular during the steady bursting period $(B) . c$, Extracellular recordings during the $S, T$, and $B$ periods described in $b$ are shown on an expanded time scale. $d$, A single cycle of the trimodal pattern from a different Purkinje neuron is shown. Top trace, Average firing rate; bottom trace, interspike intervals. $e$, The plot of interspike intervals shown in $d$ has been expanded to show more clearly the end of the steady firing period and the bursting period. $f$, Interspike intervals during the bursting period. Each burst consists of $\sim 10$ spikes/sec. only after a silent period, which in this cell lasted for $\sim 20 \mathrm{sec}$. Among all neurons with the trimodal pattern of activity, the average firing rate at the beginning of the monotonic period was $36 \pm 5$ spikes/sec (range, 5-145 spikes/sec), and the average firing rate just before start of the burst mode was $98 \pm 11$ spikes/sec (range, 18-231 spikes/sec).

The properties of the trimodal pattern of activity can be better appreciated by studying interspike intervals (Fig. $2 d-f$ ). Interspike intervals decreased regularly during the tonically firing period, corresponding to an increase in the rate of firing (Fig. 2d). After an initial period of irregular interburst intervals, bursting behavior became very regular. As the bursting progressed, the interburst intervals steadily increased until the cell ceased to fire (Fig. 2e). In each cell, the firing rate was, on average, higher during the bursts than during the tonically firing period and increased within each burst (Fig. $2 e, f$ ). The duration of a complete cycle, consisting of the tonically firing, bursting, and silent modes, varied from $20 \mathrm{sec}$ to $20 \mathrm{~min}$ in different cells but remained the same in each cell. Although there was cell-to-cell variation in the fraction of time spent in each of the three modes, all cells with the trimodal pattern showed the same progression among the three different activity modes.

It is proposed that the trimodal pattern of activity is an intrinsic property of cerebellar Purkinje neurons; any network activity would be disrupted under our experimental conditions in which fast synaptic inputs are blocked. It is also unlikely that the trimodal pattern of activity is seen only in damaged cells. The extensive dendritic arborization of Purkinje neurons has a planar, almost two-dimensional, architecture (Palay and Chan-Palay, 1974) such that minimal damage is done to the cell body and the dendrites in sagittal cerebellar slices used here. Furthermore, neurons near the surface of the slice, which would be more likely to sustain damage, were no more likely to have the trimodal pattern of activity than neurons in deeper locations (data not shown). In fact, there seemed to be a negative correlation between the percentage of Purkinje neurons with the trimodal pattern and the overall health of the slice; on occasions in which, as a result of poor slicing, there were few live Purkinje neurons on the surface of the slice, the majority of the remaining Purkinje neurons fired tonically. Moreover, the trimodal pattern emerged in three tonically firing neurons only after superfusion of kynurenic acid and picrotoxin (Fig. 1d). It is difficult to imagine that block of glutamatergic and GABAergic receptors would make otherwise healthy neurons unhealthy. Collectively, these findings force one to exclude cell damage as the cause of the trimodal pattern of activity.

Of the 202 cells tested, 5 Purkinje neurons continued to burst irregularly after superfusion of both blockers and ceased to fire after 5-10 min. It is likely that these cells were damaged by the slicing procedure, because all other cells continued to fire for as long as the recordings were maintained.

\section{The trimodal pattern of activity emerges concurrent with maturation of dendrites}

The cerebellum matures postnatally, and we find that expression of the trimodal pattern is developmentally regulated. None of the Purkinje cells studied in 10- or 11-d-old animals had the trimodal pattern; all the cells fired tonically for at least 15 min (Fig. 3a). The fraction of cells expressing the trimodal pattern increased with age from 12 to $20 \mathrm{~d}$ postnatally and remained high in adult animals. Thus the majority of cells in animals older than $16 \mathrm{~d}$ had the trimodal pattern (Fig. 3a). There was no apparent correlation between the age of the animal and the single-cycle duration (Fig. $3 b$ ) or the firing frequency at the beginning of the tonically firing phase (Fig. $3 c$ ) in the cells with the trimodal pattern. In the tonically firing cells, however, there was an increase in average firing rate over the same age range (Fig. 3c). Intriguingly, the age dependence of the expression of the trimodal pattern in Purkinje cells is concurrent with the development of dendrites, particularly the increase in dendritic arborization that occurs at this time (Altman, 1972; Ito, 1984).

\section{Cells without the trimodal firing pattern do not have lower firing rates}

In neurons with the trimodal pattern, the tonically firing phase begins with a low firing rate, which increases until the cell starts 
Figure 3. Expression of the trimodal activity pattern is developmentally regulated. $a$, Age versus fraction of Purkinje neurons that exhibit the trimodal pattern of activity. The fraction of cells with the pattern increases with the age of the animal. The number in parentheses indicates the number of cells studied at each age. Adult refers to animals older than 3 months. A cell was considered not to have the pattern if it fired tonically for at least $15 \mathrm{~min}$ without exhibiting a silent period or bursting. $b$, Age versus single-cycle duration for neurons with the trimodal pattern of activity. $c$, Comparison of the average firing rate in neurons with and without the trimodal firing pattern. The average firing rate of neurons without the pattern ( filled circles; $n=40$ ) and the average of the firing rate for the first $500 \mathrm{msec}$ of the tonically firing period (open circles; $n=54$ ) are shown. Error bars indicate SEM. $d$, Autocorrelogram for a cell with the trimodal pattern, which had a low coefficient of variation. Inset, Extracellular voltage record. $e$, Autocorrelogram for a cell with the trimodal pattern, which had a high coefficient of variation. Inset, Extracellular voltage record. $f$, Coefficient of variation versus age for all cells. The coefficient of variation was calculated from $5 \mathrm{sec}$ of data in the cells with the trimodal pattern ( filled symbols).
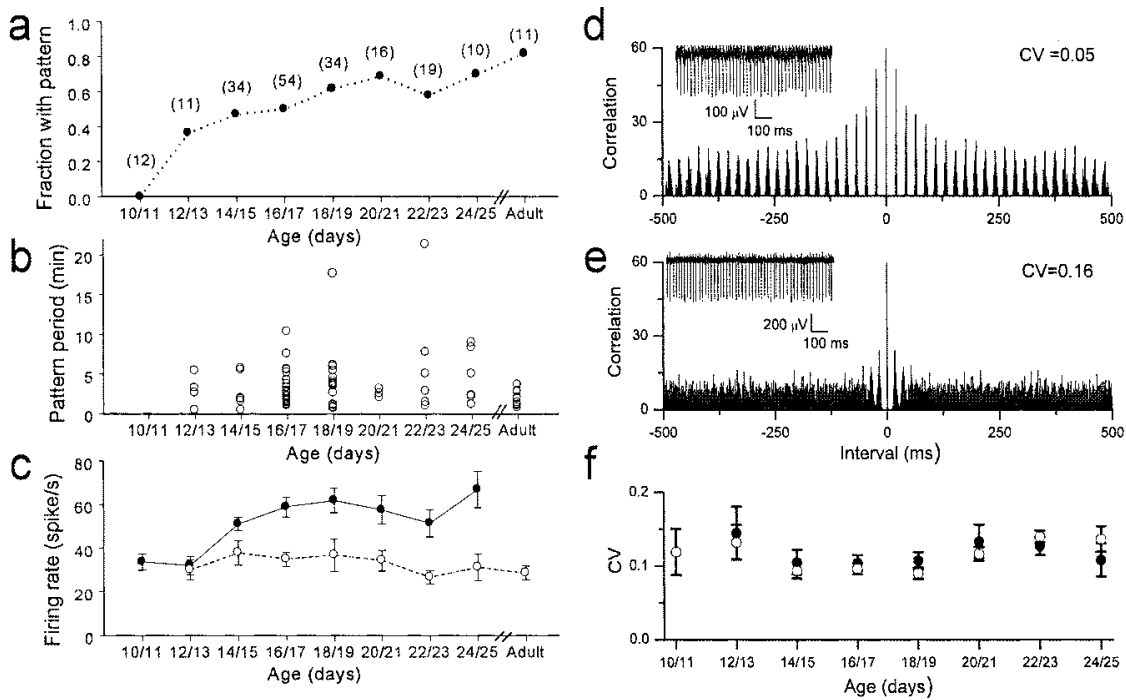

bursting. It is possible that in the neurons that lack the trimodal pattern, the tonically firing phase starts at such a low rate that the neurons never reach the firing rate necessary for bursting. This is unlikely, because the average firing rate of neurons without the trimodal firing pattern is, in fact, higher than the average firing rate at the start of the tonically firing phase in neurons with the trimodal pattern (Fig. $3 c$ ). Thus, although the tonically firing cells are still capable of firing at high rates, they do not express the trimodal pattern.

\section{Cells with and without the firing pattern have a similar coefficient of variation}

To measure the regularity of firing, we computed the autocorrelation function for $5 \mathrm{sec}$ of data from the tonically firing cells or $5 \mathrm{sec}$ at the beginning of the tonically firing period in cells with the trimodal pattern. Clear and regularly spaced peaks in the autocorrelogram were observed for most cells (Fig. $3 d$ ). This was associated with a low coefficient of variation for the interspike intervals calculated for the same data. On average, both tonically firing cells and cells with the trimodal pattern have a low coefficient of variation (Fig. $3 f$ ), although there was a wide range (0.02-0.40). Lack of distinct peaks in the autocorrelogram was always associated with a greater coefficient of variation (Fig. 3e).

\section{The firing rate in the cells with the trimodal pattern is very sensitive to temperature}

The spontaneous activity of Purkinje cells is very sensitive to changes in the temperature. In the tonically firing cells, the firing rate was a linear function of temperature in the range of $35-25^{\circ} \mathrm{C}$ (Fig. 4a). In contrast, in the cells with the trimodal pattern, reducing the temperature from $35^{\circ} \mathrm{C}$, sometimes by as little as $3^{\circ} \mathrm{C}$ (range $3-7^{\circ} \mathrm{C}$ ), caused the cells to stop firing (Fig. $4 a, b$ ).

\section{The firing pattern is not driven by type 1 metabotropic glutamate or $\mathrm{GABA}_{\mathrm{B}}$ receptors}

Synaptically released glutamate and GABA would activate not only ionotropic receptors but also their corresponding G-proteincoupled metabotropic counterparts. Purkinje cells express both $\mathrm{GABA}_{\mathrm{B}}$ metabotropic receptor and metabotropic glutamate receptor 1 (mGluR1), and it is plausible that activation of these receptors is responsible for the trimodal pattern of activity. To rule out this possibility, experiments were done during which, in addition to the glutamate and GABA ion channel blockers (2S)-3-[[(1S)-1-(3,4-dichlorophenyl)ethyl]amino-2-hydroxypropyl](phenylmethyl)phosphinic acid $(1 \mu \mathrm{M})$, a specific antagonist of $\mathrm{GABA}_{\mathrm{B}}$ receptors (Davies et al., 1993), and PHCCC (20 $\left.\mu \mathrm{M}\right)$, a wide-spectrum mGluR1 antagonist (Annoura et al., 1996), were added to the bathing medium. In all cells tested $(n=3)$, addition of glutamate and GABA metabotropic receptor antagonists did not abolish the trimodal pattern of activity (Fig. $5 a$ ).

\section{The firing pattern is not driven by diffuse release of neuromodulators}

Although glutamate and GABA receptors were pharmacologically blocked, no attempts were made to alleviate the influence of other neurotransmitters on Purkinje cells. The cerebellum receives noradrenergic, serotinergic, histaminergic, and cholinergic fibers (Ito, 1984; Dietrichs et al., 1994; Jaarsma et al., 1997), and it is possible that the trimodal pattern is caused by cyclical diffuse release of these neurotransmitters. If this were the case, then one would anticipate that the firing patterns in neighboring Purkinje cells would be synchronized. By careful positioning of the recording pipette, it was often possible to resolve, based on the differential amplitude of spikes, the firing pattern of two or three cells. In these experiments, neighboring Purkinje cells had trimodal patterns of different durations and out of phase (Fig. 5b). Furthermore, cells with the trimodal firing pattern were found adjacent to cells that fired tonically (data not shown). Thus, it seems unlikely that the trimodal firing pattern is driven by cyclical diff use release of a neurotransmitter. To unequivocally rule out the possibility of neuromodulation as the origin of the trimodal pattern, it would be necessary to pharmacologically block all known receptors or to somehow prevent the extracellular release of all chemical transmitters. Such a task is not practical at present.

The arguments presented here do not rule out the possibility that an extracellular chemical messenger might be required for the initiation or maintenance of the trimodal pattern or both, but they do suggest that if such an extracellular chemical messenger is required, then (1) the cyclical nature of the trimodal pattern is 

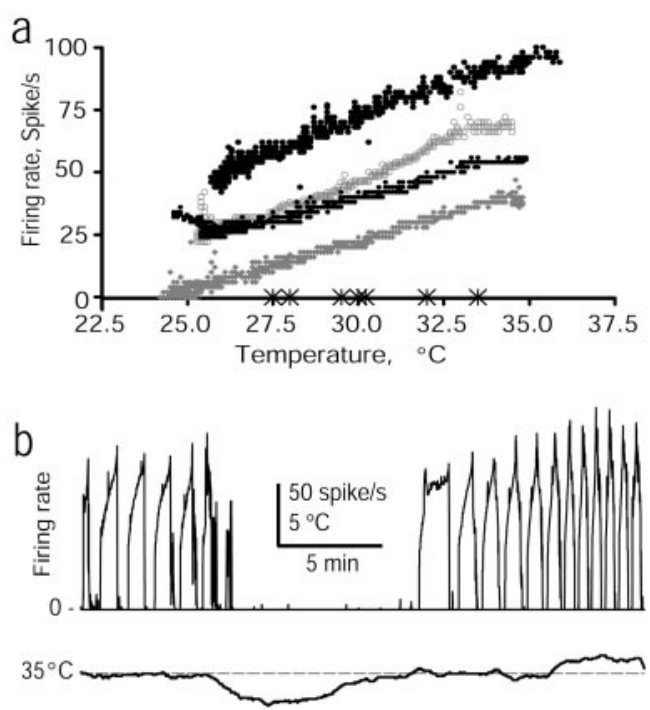

Figure 4. The firing pattern is critically temperature-dependent. $a$, The graphs show the spontaneous firing rate of four tonically firing cells as the temperature was reduced from $35^{\circ} \mathrm{C}$. In each cell, the rate of firing simply scaled down as the temperature was reduced. The cross symbols on the $x$-axis denote the temperatures at which firing ceased in seven different cells that had the trimodal pattern of activity as the temperature was reduced from $35^{\circ} \mathrm{C} . b$, Effect of temperature (bottom trace) on the spontaneous firing rate of a neuron with the pattern (top trace). A small reduction in the temperature completely stopped spontaneous activity, whereas an increase in the temperature increased the firing rate and reduced the cycle duration of the pattern.

not the consequence of changes in the concentration of this chemical, and (2) whether a cell fires tonically or with the trimodal pattern in response to the chemical depends on the intrinsic properties of the cell.

\section{The trimodal pattern of activity is not driven by the hyperpolarization-activated current}

In many neurons cyclical activity is driven by the hyperpolarization-activated current $\left(I_{\mathrm{h}}\right.$; Dietrichs et al., 1994; Annoura et al., 1996; McCormick and Bal, 1997), which is present in Purkinje cells (Crepel and Penit-Soria, 1986; Roth and Hausser, 2001), and affects its firing (Williams et al., 2002). We tested whether $I_{\mathrm{h}}$ was also responsible for the trimodal pattern of activity seen in Purkinje cells. We found that neither cesium (1 mM; Annoura et al., 1996) nor a $100 \mu \mathrm{M}$ concentration of the specific $I_{\mathrm{h}}$ blocker ZD7288 (Satoh and Yamada, 2000) abolished the trimodal pattern of activity (Fig. $5 c$ ), although they both decreased the single-cycle duration ( $n=3$ for each blocker). Thus, the trimodal pattern of activity in Purkinje neurons is not driven by $I_{\mathrm{h}}$.

\section{Calcium entry through $P / Q$ channels is required for spontaneous activity of Purkinje cells}

Voltage-gated calcium channels have also been shown to drive oscillating patterns of activity in many neurons (Llinas, 1988; Huguenard, 1996; McCormick and Bal, 1997). We tested the contribution of calcium channels to the spontaneous firing of Purkinje cells by blocking the channels with cadmium. In all tonically firing cells tested $(n=11)$, the addition of $100 \mu \mathrm{M}$ cadmium made the cells burst at high firing rates and then cease firing (Fig. 6a). Similarly, $100 \mu \mathrm{M}$ cadmium made the cells with the trimodal pattern of activity burst at high firing rates and then cease activity (Fig. $6 b ; n=11$ ). The same observation was made

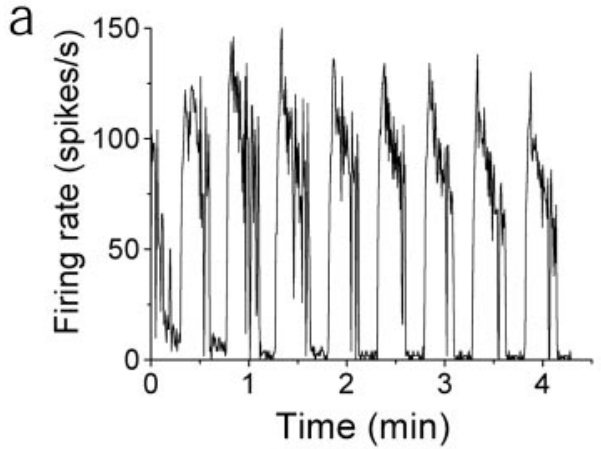

b
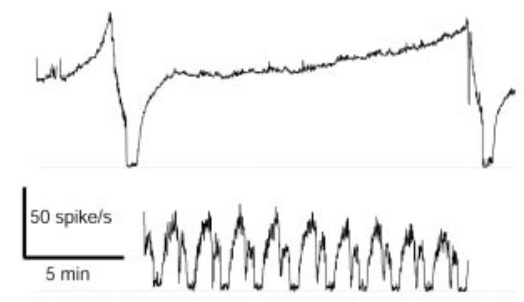

C
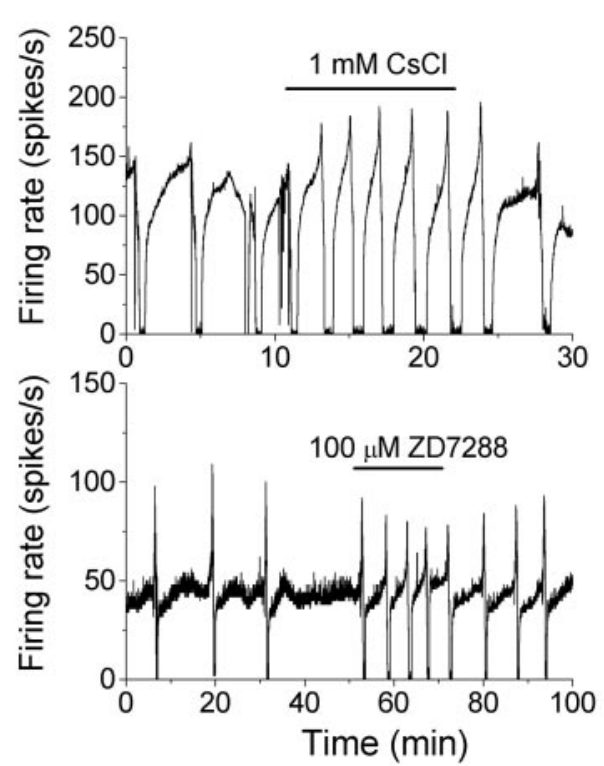

Figure 5. The trimodal pattern of activity is an intrinsic property of Purkinje cells. $a$, Average firing rate of a Purkinje neuron that exhibited the trimodal pattern. Data were recorded in the presence of $\mathrm{GABA}_{\mathrm{B}}$ and mGluR1 antagonists as well as fast synaptic blockers. $b$, The firing activity of two neighboring Purkinje cells that exhibited the trimodal pattern was simultaneously monitored on the basis of their differential spike amplitudes. Although one Purkinje cell had a single-cycle duration of $>17 \mathrm{~min}$ (top trace), the cycle duration of an adjoining cell (bottom trace) was $<2$ min. $c$, Average firing rate of two Purkinje neurons with the trimodal pattern. Application of $I_{\mathrm{h}}$ blockers shortened the single-cycle duration but did not abolish the pattern.

in two additional cells with the trimodal pattern of activity in which $100 \mu \mathrm{M}$ cobalt was used instead of cadmium (data not shown). The effects of cadmium or cobalt could be reproduced by $1 \mu \mathrm{M} \omega$-conotoxin MVIIC ( $\omega$ CgTxMV IIC), a specific antagonist of P/Q- and N-type calcium channels (McDonough et al., 1996) in both the tonically firing cells $(n=2)$ (Fig. $6 c)$ and the cells with the trimodal pattern of activity $(n=3)$ (Fig. $6 d$ ). The effects of the $\mathrm{P} / \mathrm{Q}$-selective toxin $\omega$-agatoxin (Aga) IVA (100 nM) on the firing rate of Purkinje cells were identical to those of $\omega$-conotoxin 
MVIIC (Fig. 6e,f) suggesting that P/Q- and not N-type calcium channels were required to sustain activity in Purkinje cells $(n=$ 4 tonically firing cells; $n=3$ cells with the pattern).

The inhibition of cellular activity after block of $\mathrm{P} / \mathrm{Q}$ channels either may be attributable to loss of the inward calcium current or may be a consequence of depolarization block if the net effect of calcium entry is to hyperpolarize the membrane by activating calcium-activated potassium channels. The latter possibility is supported by the finding that substitution of extracellular calcium with barium fails to support spontaneous firing in Purkinje neurons (data not shown), and that on rare occasions when spontaneous firing of dissociated Purkinje cells is arrested by cadmium or cobalt, it returns after injection of a hyperpolarizing current (Raman and Bean, 1997).

\section{Dendrites contribute to the spontaneous firing of Purkinje cells}

It is becoming increasingly evident that dendrites, both because of their complicated electrotonic structure as well as the selective localization of voltage-gated ion channels, play an important role in regulating both spontaneous and synaptically evoked activity in many neurons (Llinas, 1988; Spruston et al., 1999). There is good evidence that many types of voltage-gated channels are present in the dendrites of neurons and actively contribute to excitability (Llinas, 1988; Westenbroek et al., 1990, 1992; Jaffe et al., 1992; Llinas et al., 1992; Miyakawa et al., 1992; Markram and Sakmann, 1994; Stuart and Sakmann, 1994; Magee et al., 1995; Magee and Johnston, 1995a,b; Destexhe et al., 1996; Eilers and Konnerth, 1997; Magee, 1999, 2000; Johnston et al., 2000). Given that the emergence of the trimodal pattern of activity is concurrent with the maturation of the dendrites, we evaluated the role of dendrites in the spontaneous activity of tonic and trimodal pattern cells. To do so, we eliminated the electrical contribution of parts of the dendrites to the soma by locally applying onto them a solution that did not contain any ions (isotonic sucrose). In the absence of ions in the perfusate, there are no charges to carry electrical current (the only possible source of electrical charge would be leakage of ions out of the cell, which is likely to be quite minor). Therefore, there is neither a membrane potential nor any electrical current flow across the membrane exposed to isotonic sucrose. Thus, the area covered by the perfusate is electrically isolated from the soma and does not contribute to its excitability. The area exposed to isotonic sucrose was confined with the aid of a local suction pipette and was identified by the inclusion of inert color compounds (either fast green or phenol red). In a series of control experiments, changes in the DC potential at the recording pipette were used to monitor the spatial distribution of the sucrose. Moving the tip of the recording pipette from the edge of the dye front to the center of the stream caused an increase in the recorded DC potential, quickly leading to amplifier saturation. With this technique, it was determined that the visible dye front was an accurate indicator of the localization of the perfusate.

In the tonically firing cells, elimination of the electrical contribution of the dendrites to spontaneous firing either had little effect or simply reduced the firing rate. Figure $7 a$ shows an example in which the dendrites made little contribution to spontaneous firing. Electrical isolation of the distal half of the dendrites had no effect on spontaneous firing (Fig. 7a, red traces), whereas removal of the distal two-thirds reduced the rate of spontaneous activity from 33 to 29 spikes/sec (Fig. 7a, blue traces). Application of isotonic sucrose to the entire cell immediately prevented detection of electrical activity of the cell because, in a

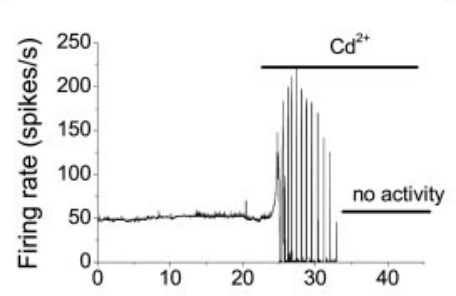

b
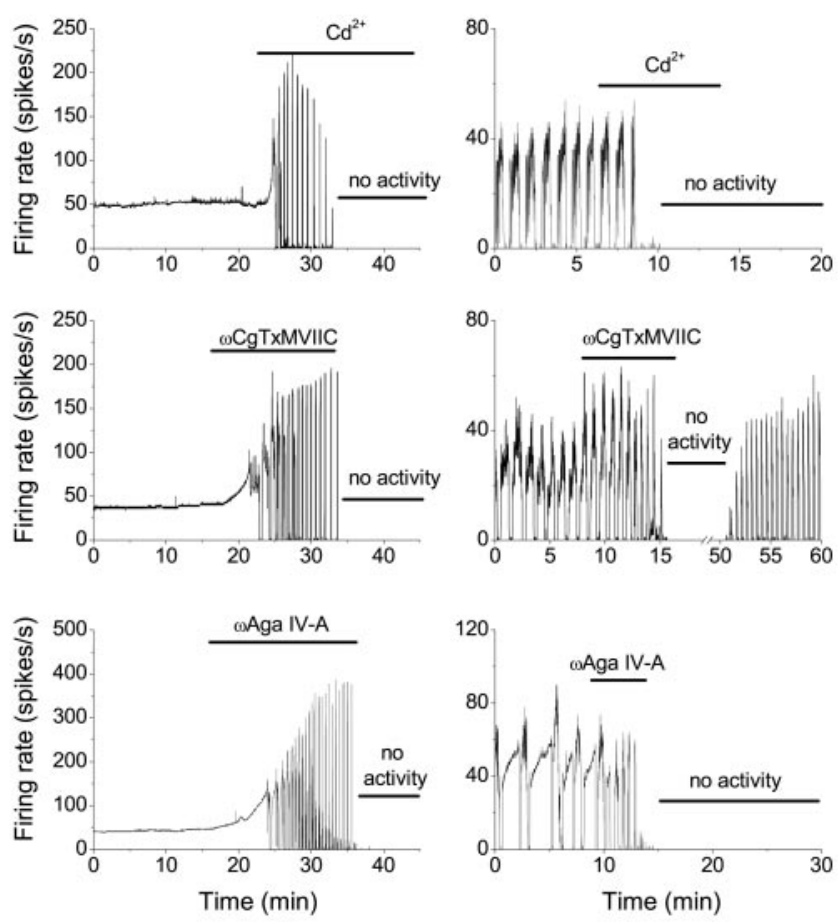

Figure 6. Voltage-gated calcium channels, particularly the $\mathrm{P} / \mathrm{Q}$ type, are required for spontaneous firing in Purkinje neurons. $a$, In a tonically firing Purkinje neuron, bath application of $\mathrm{CdCl}_{2}(100 \mu \mathrm{M})$ to block voltagegated calcium channels caused the cell to burst and then go silent. $b$, Block of voltage-gated calcium channels by application of $\mathrm{CdCl}_{2}(100 \mu \mathrm{M})$ also inhibited firing in a Purkinje neuron that expressed the trimodal pattern of activity. $c$, Bath application of $1 \mu \mathrm{M} \omega \mathrm{CgTx}$ MVIIC to a tonically firing Purkinje neuron caused the cell to burst and then go silent. $d$, Application of $\omega \mathrm{CgTxMVIIC}(1 \mu \mathrm{M})$ to a Purkinje neuron that expressed the trimodal pattern inhibited firing. $e$, Bath application of $100 \mathrm{nM} \omega$ Aga IV-A to a tonically firing Purkinje neuron initially increased the firing rate and then caused it to burst and go silent. $f$, Application of $100 \mathrm{~nm} \omega \mathrm{Aga}$ IV-A to a Purkinje neuron with the trimodal pattern caused it to burst and go silent.

the absence of ions, the electrical potential at the site of the recording pipette was no longer defined (Fig. 7a, green traces). The latter result served as a control to show that isotonic sucrose was effective in electrically isolating the region exposed to it from the rest of the slice. Application of sucrose to the distal half of the dendrites in the tonically firing cell shown in Figure $7 b$ had a greater effect, decreasing the average firing rate from 39 to 10 spikes/sec (Fig. $7 b$, red traces). During this time, the cell continued to fire tonically without bursting (Fig. $7 b$, bottom right). Similar experiments were performed in six tonically firing cells. Electrical elimination of the distal third of dendrites had no effect in either of two cells tested. In four of the five cells tested, a reduction in the rate of tonic activity was observed when half of the dendrites were electrically isolated from the soma by isotonic sucrose. In all three cells in which the distal two-thirds were exposed to isotonic sucrose, a reduction in the rate of tonic activity was seen, although the cells never showed any periods of bursting. Thus in tonically firing cells dendrites provide a net inward current to the soma during spontaneous activity.

Electrical isolation of distal dendrites from the soma in the cells with the trimodal pattern had a different effect on spontaneous firing. Figure $7 c$ shows one such experiment in which the 
distal half of the dendrites of a cell with the trimodal pattern of activity was electrically isolated from the soma. On exposure to isotonic sucrose, the cell began to burst randomly with (relatively) long pauses between bursts (Fig. 7c, red traces). Elimination of the electrical contribution of the distal two-thirds of the dendrites resulted in more avid bursting followed by termination of activity (Fig. 7c, blue traces). These experiments were repeated in six cells with the trimodal pattern of activity with qualitatively similar results. In all the cells tested, electrical isolation of half or more of the distal dendrites made the cells burst randomly. In the one cell tested, even elimination of the electrical contribution made by the distal third of dendrites caused the cell to burst. In contrast, elimination of the electrical contribution of dendrites to the tonically firing cells never caused the cells to burst or to stop firing.

It should be noted that in none of the experiments described was the amplitude of the extracellular spikes affected by the local perfusion of sucrose on the dendrites. This observation is agreement with our control experiments using the DC potential to check the extent of perfusion and suggest that there were no changes in the sodium concentration bathing the soma.

\section{Dendritic calcium channels contribute to the spontaneous firing in neurons with the pattern but not in the tonically firing ones}

Given the differential contribution of dendrites to the electrical activity of Purkinje cells with and without the trimodal pattern of activity, we evaluated the contribution of dendritic voltage-gated calcium channels to excitability in each cell type. Localized perfusion of $100 \mu \mathrm{M}$ cadmium to the distal half of the dendrites in a tonically firing Purkinje cell resulted in a very small increase in the firing rate (Fig. $8 a$, red trace). Superf usion of the whole cell with cadmium, however, made the cell burst and cease firing (Fig. $8 a$, blue trace). This result is similar to the results obtained when cadmium was bath-applied (Fig. $6 a$ ). Perfusion of cadmium onto the dendrites had similar negligible effects in all three tonically firing cells tested.

Localized perfusion of cadmium onto the dendrites of the cells with the trimodal pattern of activity, however, had quite different effects. The result of one such experiment is shown in Figure $8 b$. Application of cadmium to the distal half of the dendritic tree caused the cell to burst (Fig. $8 b$, red traces). When the area of cadmium perfusion was increased to cover two-thirds of the dendrites, the cell stopped all activity (Fig. $8 b$, blue traces). The cell partially recovered its normal firing pattern when localized perfusion was discontinued (Fig. 8b, black traces). In these experiments great care was taken to make sure that the soma and proximal dendrites were not exposed to cadmium. Exposure of distal dendrites to cadmium was sufficient to inhibit firing in all cells with the trimodal pattern of activity $(n=3)$. The inhibition of activity after block of dendritic voltage-gated calcium channels either may be attributable to a loss of an inward calcium current required to maintain spontaneous firing or may be a consequence of depolarization block if the net effect of calcium entry is to activate a dominant outward current via calcium-activated potassium channels. If the reason for loss of activity in these experiments is depolarization block, it follows that either the net electrical contribution of the dendrites is to hyperpolarize the soma of Purkinje cells (in contrast to a net inward current in tonically firing cells), or that dendritic calcium diffuses to the soma to activate somatic calcium-activated potassium channels.
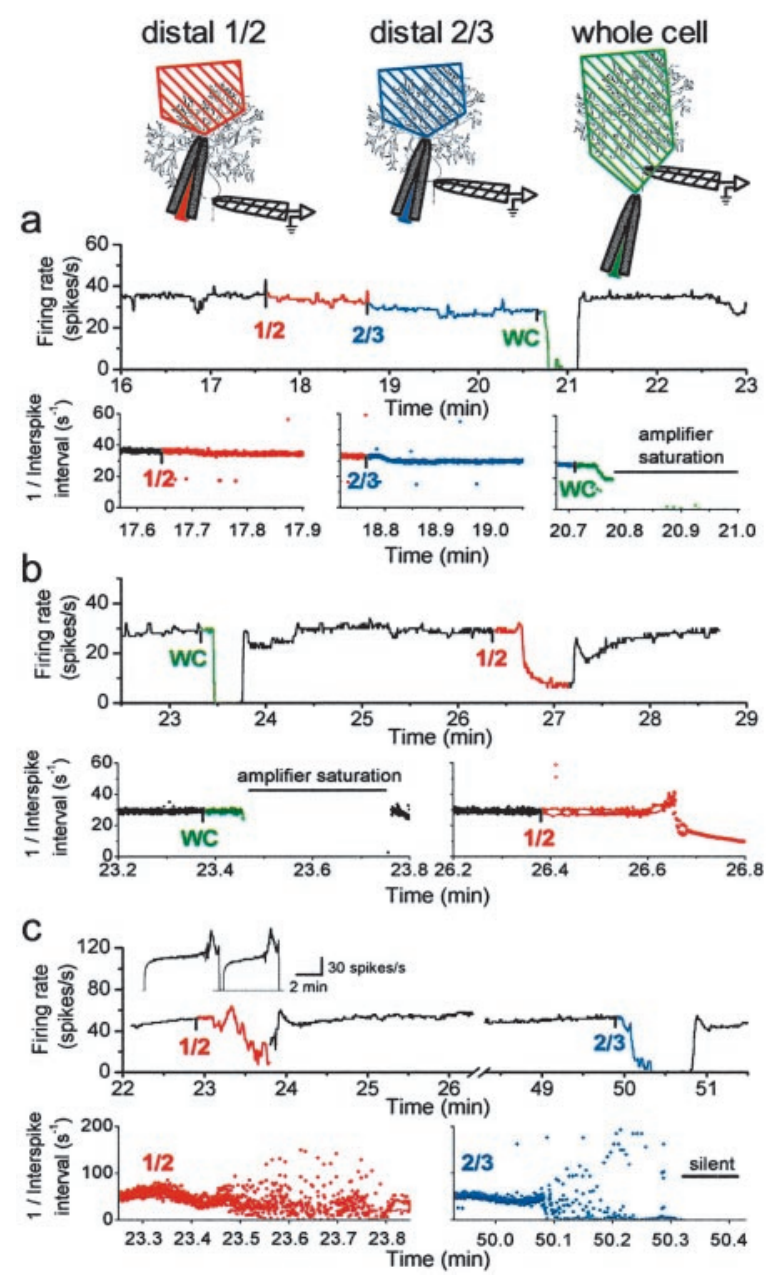

Figure 7. Dendrites contribute to the spontaneous firing of Purkinje neurons with the trimodal pattern of activity. $a$, A solution devoid of ions (isotonic sucrose) was perfused locally onto the dendrites to electrically isolate segments of the dendrites from the soma in a tonically firing neuron. Diagrams at the top show the placement of the perfusion and recording pipettes relative to the Purkinje neuron and the approximate area of the dendrites exposed to sucrose. The top data record shows the average firing rate, and the bottom data records show the instantaneous firing rate [1/(interspike interval)]. Application of isotonic sucrose to the distal half of the molecular layer had little effect on the firing rate $(1 / 2$, red traces). When two-thirds of the molecular layer were exposed to isotonic sucrose, the firing rate decreased slightly (2/3, blue traces). Application of isotonic sucrose to the entire cell, including the tip of the recording pipette (WC, green traces), immediately prevented detection of electrical activity of the cell. $b$, Application of sucrose to the dendrites of another tonically firing neuron. When applied to the distal half of the dendrites $(1 / 2$, red traces $)$, the firing rate decreased, with no bursts or pauses. $c$, Isotonic sucrose was locally perfused onto the dendrites of a Purkinje neuron with the trimodal pattern (inset, average firing rate for 2 cycles of the pattern). Application of isotonic sucrose to the distal half of the molecular layer caused an apparent decrease in the average firing rate $(1 / 2$, top record, red trace) and caused the cell to burst irregularly (1/2, bottom left, red trace). When isotonic sucrose was applied to the outer two-thirds of the molecular layer, the cell burst irregularly for $\sim 20 \mathrm{sec}$ before it ceased firing $(2 / 3$, blue traces $)$.

The results presented in this section suggest that dendritically located voltage-gated calcium channels make a significant contribution to the firing pattern of Purkinje cells with the trimodal pattern of activity, whereas the channels do not play a large role in the tonically firing cells. 


\section{DISCUSSION}

Motor coordination is thought to be achieved by changes in the activity of cerebellar Purkinje neurons (Eccles et al., 1967a; Marr, 1969; Albus, 1971; Ito, 1984). There is no doubt that Purkinje neurons are intrinsically active (Hausser and Clark, 1997; Nam and Hockberger, 1997; Raman and Bean, 1997; Jaeger and Bower, 1999), and that their spontaneous activity is regulated by their excitatory and inhibitory synaptic inputs (Granit and Phillips, 1956; Eccles et al., 1966, 1967b; Armstrong and Rawson, 1979; Ito, 1984; Jaeger and Bower, 1994; Hausser and Clark, 1997; Jaeger and Bower, 1999). What is less clear is whether, intrinsically, Purkinje cells are capable of altering their mode of activity (i.e., tonically firing vs bursting or silence) or firing rate.

Here we report that not all of the switches among tonically firing, bursting, and silent modes seen in Purkinje cells in cerebellar slices are the consequence of glutamatergic and GABAergic synaptic inputs, but that some arise because of an intrinsic, trimodal pattern of activity. The trimodal pattern of activity emerges concurrent with maturation of the cerebellum and is effectively unmasked by preventing the modulation of excitability of Purkinje cells by glutamate and GABA ionotropic receptors. Localized perfusion studies reveal that the dendrites play a significant role in regulating the firing of Purkinje neurons, particularly those with the trimodal pattern of activity.

\section{Dendritic maturation may underlie expression of the trimodal pattern of activity}

Given the increased role of dendrites in modulating the spontaneous activity of the cells with the trimodal pattern and the increase in the percentage of cells with the trimodal pattern concurrent with maturation of the dendrites, an intriguing possibility is that maturation of the dendrites is required for expression of the trimodal pattern of activity. Emergence of the trimodal pattern of activity might result from increased expression of a dendritically delimited ion channel as the dendrites mature or may require changes in the electrotonic architecture of the cell because of changes in the dendritic arborization. Because in Purkinje neurons expression of many ion channels is developmentally regulated (Gruol et al., 1992; Xia and Haddad, 1994; Sashihara et al., 1995; Felts et al., 1997; Muller and Yool, 1998; Muller et al., 1998), the former proposal, particularly increased expression of a voltage-gated calcium channel (Gruol et al., 1992), is a more likely possibility.

It is important to note, however, that the dendrites do not simply impose the trimodal pattern on a tonically firing soma. Functional elimination of the electrical contribution of the dendrites in a cell with the trimodal pattern did not result in a tonically firing soma but ceased all activity in the cell. This suggests that functional maturation of Purkinje cells entails more than just increased expression of an ion channel in the dendrites and necessitates additional changes in the soma, proximal dendrites, or both.

\section{Comparison with literature}

The firing behavior of Purkinje neurons has been studied extensively both in vivo and in vitro. In adult guinea pig cerebellar slices, intracellular recording shows a cyclical pattern of firing comprising alternating periods of bursting and silence, each of which lasts 5-15 sec (Llinas and Sugimori, 1980a,b; Tank et al., 1988; Lev-Ram et al., 1992; Jaeger and Bower, 1994). This cyclical pattern has been observed with extracellular recordings that cause minimal damage to, or compression of, the cell (Llinas and
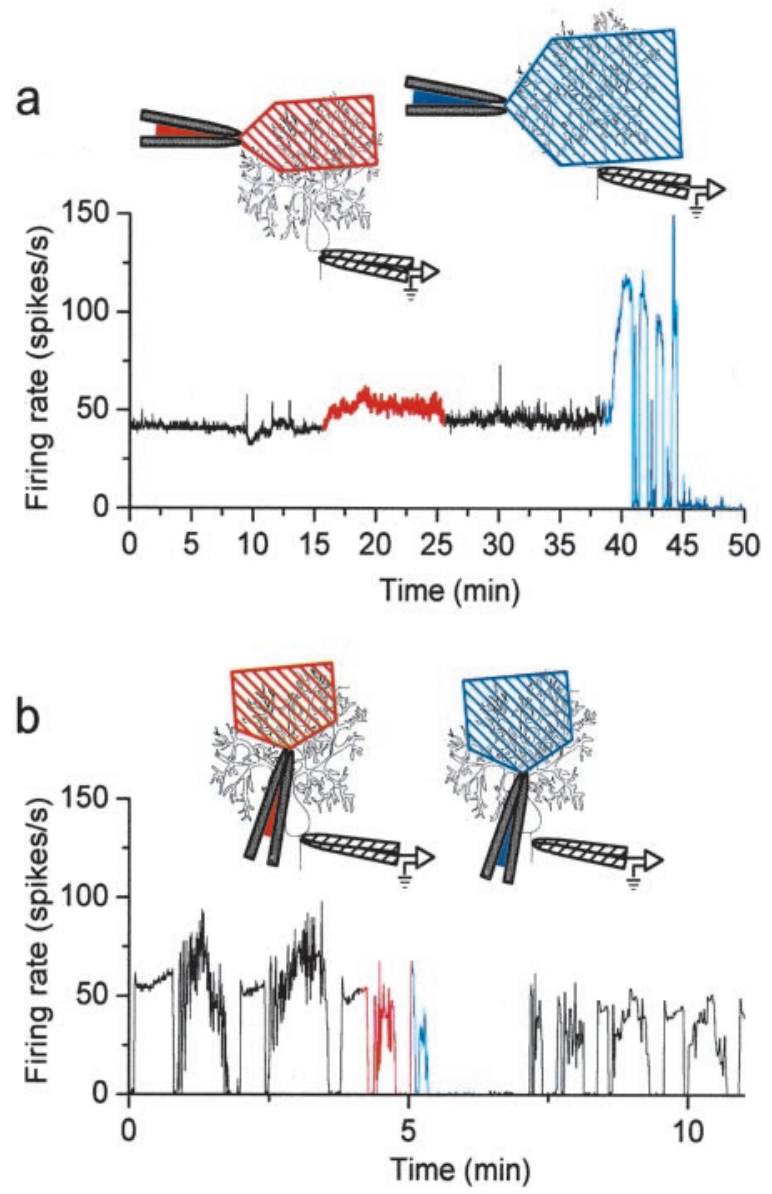

Figure 8. Dendritic calcium channels are required for spontaneous firing of Purkinje neurons with the trimodal pattern. $a$, An external solution containing $\mathrm{CdCl}_{2}(100 \mu \mathrm{M})$ was perfused locally onto the dendrites of a tonically firing Purkinje neuron. Diagrams at the top show the placement of the perfusion and recording pipettes relative to the Purkinje neuron and the approximate area of the dendrites exposed to $\mathrm{Cd}^{2+}$. Application of $\mathrm{Cd}^{2+}$ to the outer half of the molecular layer caused a small increase in the average firing rate of the cell (red trace). Application of $\mathrm{Cd}^{2+}$ to the entire cell caused the cell to burst for several minutes and then stop firing (blue trace). $b, \mathrm{CdCl}_{2}$ was applied locally to the dendrites of a cell with the trimodal pattern. Application of $\mathrm{Cd}^{2+}$ to the distal half of the dendrites caused the cell to burst (red trace). When $\mathrm{Cd}^{2+}$ was applied to the outer two-thirds of the molecular layer, the cell stopped firing (blue trace).

Sugimori, 1980a,b). A similar pattern of spontaneous activity has also been suggested to be present in Purkinje neurons studied with whole-cell recording in slices of rat cerebellum (Jaeger and Bower, 1999). These observations are extended in the present report by the demonstration that, in the absence of rapid synaptic input, a cyclical pattern of spontaneous firing and quiescence is a property of most adult Purkinje neurons. Additionally, we find that the period of firing consists of long tonically firing and bursting modes. The single-cycle duration of the trimodal pattern is an intrinsic property of each neuron and remains the same for hours during recording but varies widely among different neurons. A similar trimodal pattern of activity is also seen in rats (M. Womack and K. Khodakhah, unpublished observations; T. Otis, personal communication; S. Vijayraghavan, personal communication). A trimodal pattern is also observed when low concentrations of CNQX and APV are used to block fast excitatory input instead of kynurenic acid (data not shown). 
Hausser and Clark (1997), using extracellular or cell-attached recording, reported that most Purkinje neurons in rat slices fire tonically with $<5 \%$ of cells showing bursts or long periods of inactivity even in the presence of a $\mathrm{GABA}_{\mathrm{A}}$ antagonist. Although this finding of Hausser and Clark (1997) is in contrast to ours and those of Llinas and Sugimori (1980a,b) and Jaeger et al. (1997), the objectives of their studies were not to characterize the spontaneous firing behavior of Purkinje cells but to identify the relative contribution of excitatory and inhibitory inputs on the regularity of firing. Accordingly, most of their recordings were of shorter duration than ours (M. Hausser and B. A. Clark, personal communication), and it is conceivable, therefore, that cells with the trimodal pattern were classified as firing tonically.

In vivo, Purkinje neurons typically fire tonically at an irregular rate with occasional pauses and single bursts associated with climbing fiber input. In our experiments, we find that pharmacological removal of fast synaptic input from some tonic cells reveals a trimodal pattern of activity. A similar phenomenon has also been reported in vivo in which Jaeger and Bower (1994) reported that pharmacological removal of fast inhibitory synaptic input changes a tonically firing Purkinje neuron to one in which the cells cycle between "a hyperpolarized, quiescent state and periods of sodium and calcium spike bursts." Using an active membrane model of a morphologically reconstructed Purkinje neuron, De Schutter and Bower (1994) found that in the absence of synaptic input, a continuous somatic current injection results in a progressive increase in the firing frequency followed by bursting. Addition of random inhibitory inputs to the model prevents this behavior and yields a tonically firing cell that fires irregularly, similar to that seen in vivo (De Schutter and Bower, 1994; Jaeger et al., 1997). Our results are in agreement with this model, although in contrast to the model, we find that no current injection is necessary in vitro to observe the trimodal pattern of activity. One reason for this difference may be that a resurgent sodium current was not included in the model. This current is proposed to be required for spontaneous activity of Purkinje neurons (Raman and Bean, 1997; Raman and Bean, 1999a,b). Indeed, the model of De Schutter and Bower (1994) does not fire action potentials spontaneously in the absence of injection of a continuous inward current, whereas real Purkinje cells do.

The increase in the rate of firing and the subsequent bursts seen in the model of De Schutter and Bower (1994) in response to continuous current injection has also been observed experimentally in Purkinje cells in vitro (Llinas and Sugimori, 1980a). Both in the model and in the actual experiments done by Llinas and Sugimori (1980a), the bursts are associated with dendritic calcium spikes. A working hypothesis to explain this progression is based on a push-pull mechanism first proposed by Rall (1962), in which each somatic sodium spike charges the large capacitance of the dendrites to produce a small dendritic depolarization. The dendritic depolarization outlasts that of the somatic depolarization, which is discharged rapidly by voltage-gated potassium channels. In between somatic spikes, the dendritic depolarization then results in a net flow of current from the dendrites to the soma, which helps repolarize the relatively small somatic capacitance toward the threshold. It is likely that voltage-gated dendritic channels would also contribute to the net current. As the persistent depolarization of the dendrites gets larger and larger with subsequent somatic spikes, the dendrites eventually reach the threshold for generation of calcium spikes. The dendritic calcium spikes result in the generation of bursts of somatic action potentials. Such an interplay between the soma and dendrites of Pur- kinje neurons can be seen in the model of De Schutter and Bower (1994) (also see Jaeger et al., 1997, Discussion) and may be the mechanism responsible for the generation of the trimodal pattern of activity reported here. Alternatively, the trimodal pattern of activity may be attributable to secondary effects of a second messenger, for example, calcium-dependent phosphorylation of ion channels, which cyclically alters the excitability of Purkinje neurons. Further experiments are required to distinguish between these two possibilities.

A regular trimodal pattern of activity is not observed in vivo in the presence of synaptic input. What then is the physiological significance of the trimodal pattern of activity shown? If the mechanism underlying the trimodal pattern of activity is the dendritic push-pull mechanism described above, then it is unlikely that the trimodal pattern plays a major physiological role, because this mechanism will be heavily influenced by synaptic inputs. Alternatively, however, if the trimodal pattern is mediated by changes in the excitability of the cell brought about by a second messenger, for example, by phosphorylation of ion channels, then this second messenger may regulate the excitability of Purkinje cells in vivo, although the full trimodal pattern is not evident.

\section{REFERENCES}

Albus JS (1971) A theory of cerebellar function. Math Biosci 10:25-61. Altman J (1972) Postnatal development of the cerebellar cortex in the rat. II. Phases in the maturation of Purkinje cells and of the molecular layer. J Comp Neurol 145:399-463.

Annoura H, Fukunaga A, Uesugi M, Tatsuoka, Horikawa Y (1996) A novel class of antagonists for metabotropic glutamate receptors, 7-(hydroxyimino)cyclopropal[b]chromen-1a-carboxylates. Bioorg Med Chem Lett 6:763-766.

Armstrong DM, Rawson JA (1979) Activity patterns of cerebellar cortical neurones and climbing fibre afferents in the awake cat. J Physiol (Lond) 289:425-448.

Chang W, Strahlendorf JC, Strahlendorf HK (1993) Ionic contributions to the oscillatory firing activity of rat Purkinje cells in vitro. Brain Res 614:335-341.

Crepel F, Penit-Soria J (1986) Inward rectification and low threshold calcium conductance in rat cerebellar Purkinje cells: an in vitro study. J Physiol (Lond) 372:1-23.

Davies CH, Pozza MF, Collingridge GL (1993) CGP 55845A: a potent antagonist of GABAB receptors in the CA1 region of rat hippocampus. Neuropharmacology 32:1071-1073.

De Schutter E, Bower JM (1994) An active membrane model of the cerebellar Purkinje cell. II. Simulation of synaptic responses. J Neurophysiol 71:401-419.

Destexhe A, Contreras D, Steriade M, Sejnowski TJ, Huguenard JR (1996) In vivo, in vitro, and computational analysis of dendritic calcium currents in thalamic reticular neurons. J Neurosci 16:169-185.

Dietrichs E, Haines DE, Roste GK, Roste LS (1994) Hypothalamocerebellar and cerebellohypothalamic projections-circuits for regulating nonsomatic cerebellar activity? Histol Histopathol 9:603-614.

Eccles JC, Llinas R, Sasaki K (1966) Intracellularly recorded responses of the cerebellar Purkinje cells. Exp Brain Res 1:161-183.

Eccles JC, Ito M, Szenthagothai J (1967a) The cerebellum as a neuronal machine. Heidelberg: Springer.

Eccles JC, Sasaki K, Strata P (1967b) A comparison of the inhibitory actions of Golgi cells and of basket cells. Exp Brain Res 3:81-94.

Eilers J, Konnerth A (1997) Dendritic signal integration. Curr Opin Neurobiol 7:385-390.

Felts PA, Yokoyama S, Dib-Hajj S, Black JA, Waxman SG (1997) Sodium channel alpha-subunit mRNAs I, II, III, NaG, Na6 and hNE (PN1): different expression patterns in developing rat nervous system. Brain Res Mol Brain Res 45:71-82.

Granit R, Phillips CG (1956) Excitatory and inhibitory processes acting upon individual Purkinje cells of the cerebellum in cats. J Physiol (Lond) 133:520-547.

Gruol DL, Deal CR, Yool AJ (1992) Developmental changes in calcium conductances contribute to the physiological maturation of cerebellar Purkinje neurons in culture. J Neurosci 12:2838-2848.

Hausser M, Clark BA (1997) Tonic synaptic inhibition modulates neuronal output pattern and spatiotemporal synaptic integration. Neuron 19:665-678.

Huguenard JR (1996) Low-threshold calcium currents in central nervous system neurons. Annu Rev Physiol 58:329-348.

Ito M (1984) The cerebellum and neural control. New York: Raven. 
Jaarsma D, Ruigrok TJ, Caffe R, Cozzari C, Levey AI, Mugnaini E, Voogd J (1997) Cholinergic innervation and receptors in the cerebellum. Prog Brain Res 114:67-96.

Jaeger D, Bower JM (1994) Prolonged responses in rat cerebellar Purkinje cells following activation of the granule cell layer: an intracellular in vitro and in vivo investigation. Exp Brain Res 100:200-214.

Jaeger D, Bower JM (1999) Synaptic control of spiking in cerebellar Purkinje cells: dynamic current clamp based on model conductances. J Neurosci 19:6090-6101.

Jaeger D, De Schutter E, Bower JM (1997) The role of synaptic and voltage-gated currents in the control of Purkinje cell spiking: a modeling study. J Neurosci 17:91-106.

Jaffe DB, Johnston D, Lasser-Ross N, Lisman JE, Miyakawa H, Ross WN (1992) The spread of $\mathrm{Na}^{+}$spikes determines the pattern of dendritic $\mathrm{Ca}^{2+}$ entry into hippocampal neurons. Nature 357:244-246.

Johnston D, Hoffman DA, Magee JC, Poolos NP, Watanabe S, Colbert CM, Migliore M (2000) Dendritic potassium channels in hippocampal pyramidal neurons. J Physiol (Lond) 525:75-81.

Latham A, Paul DH (1971) Spontaneous activity of cerebellar Purkinje cells and their responses to impulses in climbing fibres. J Physiol (Lond) 213:135-156.

Lev-Ram V, Miyakawa H, Lasser-Ross N, Ross WN (1992) Calcium transients in cerebellar Purkinje neurons evoked by intracellular stimulation. J Neurophysiol 68:1167-1177.

Llinas RR (1988) The intrinsic electrophysiological properties of mammalian neurons: insights into central nervous system function. Science 242:1654-1664.

Llinas R, Sugimori M (1980a) Electrophysiological properties of in vitro Purkinje cell somata in mammalian cerebellar slices. J Physiol (Lond) 305:171-195.

Llinas R, Sugimori M (1980b) Electrophysiological properties of in vitro Purkinje cell dendrites in mammalian cerebellar slices. J Physiol (Lond) 305:197-213.

Llinas R, Sugimori M, Hillman DE, Cherksey B (1992) Distribution and functional significance of the P-type, voltage-dependent $\mathrm{Ca}^{2+}$ channels in the mammalian central nervous system. Trends Neurosci 15:351-355.

Magee JC (1999) Dendritic $I_{\mathrm{h}}$ normalizes temporal summation in hippocampal CA1 neurons. Nat Neurosci 2:508-514.

Magee JC (2000) Dendritic integration of excitatory synaptic input. Nat Rev Neurosci 1:181-190.

Magee JC, Johnston D (1995a) Characterization of single voltage-gated $\mathrm{Na}^{+}$and $\mathrm{Ca}^{2+}$ channels in apical dendrites of rat CA1 pyramidal neurons. J Physiol (Lond) 487:67-90.

Magee JC, Johnston D (1995b) Synaptic activation of voltage-gated channels in the dendrites of hippocampal pyramidal neurons. Science 268:301-304

Magee JC, Christofi G, Miyakawa H, Christie B, Lasser-Ross N, Johnston D (1995) Subthreshold synaptic activation of voltage-gated $\mathrm{Ca}^{2+}$ channels mediates a localized $\mathrm{Ca}^{2+}$ influx into the dendrites of hippocampal pyramidal neurons. J Neurophysiol 74:1335-1342.

Markram H, Sakmann B (1994) Calcium transients in dendrites of neocortical neurons evoked by single subthreshold excitatory postsynaptic potentials via low-voltage-activated calcium channels. Proc Natl Acad Sci USA 91:5207-5211.

Marr D (1969) A theory of cerebellar cortex. J Physiol (Lond) 202:437-470

McCormick DA, Bal T (1997) Sleep and arousal: thalamocortical mechanisms. Annu Rev Neurosci 20:185-215.

McDonough SI, Swartz KJ, Mintz IM, Boland LM, Bean BP (1996) Inhibition of calcium channels in rat central and peripheral neurons by omega-conotoxin MVIIC. J Neurosci 16:2612-2623.

Miyakawa H, Ross WN, Jaffe D, Callaway JC, Lasser-Ross N, Lisman JE,
Johnston D (1992) Synaptically activated increases in $\mathrm{Ca}^{2+}$ concentration in hippocampal CA1 pyramidal cells are primarily due to voltage-gated $\mathrm{Ca}^{2+}$ channels. Neuron 9:1163-1173.

Muller YL, Yool AJ (1998) Increased calcium-dependent $\mathrm{K}^{+}$channel activity contributes to the maturation of cellular firing patterns in developing cerebellar Purkinje neurons. Brain Res Dev Brain Res 108:193-203.

Muller YL, Reitstetter R, Yool AJ (1998) Regulation of $\mathrm{Ca}^{2+}$. dependent $\mathrm{K}^{+}$channel expression in rat cerebellum during postnatal development. J Neurosci 18:16-25.

Nam SC, Hockberger PE (1997) Analysis of spontaneous electrical activity in cerebellar Purkinje cells acutely isolated from postnatal rats. J Neurobiol 33:18-32.

Palay SL, Chan-Palay V (1974) Cerebellar cortex. Berlin: Springer.

Rall W (1962) Electrophysiology of a dendritic neuron model. Biophys J 2:145-167.

Raman IM, Bean BP (1997) Resurgent sodium current and action potential formation in dissociated cerebellar Purkinje neurons. J Neurosci $17: 4517-4526$

Raman IM, Bean BP (1999a) Ionic currents underlying spontaneous action potentials in isolated cerebellar Purkinje neurons. J Neurosci 19:1663-1674.

Raman IM, Bean BP (1999b) Properties of sodium currents and action potential firing in isolated cerebellar Purkinje neurons. Ann NY Acad Sci 868:93-96.

Roth A, Hausser M (2001) Compartmental models of rat cerebellar Purkinje cells based on simultaneous somatic and dendritic patchclamp recordings. J Physiol (Lond) 535:445-472.

Sashihara S, Oh Y, Black JA, Waxman SG (1995) $\mathrm{Na}^{+}$channel beta 1 subunit mRNA expression in developing rat central nervous system. Brain Res Mol Brain Res 34:239-250.

Satoh TO, Yamada M (2000) A bradycardiac agent ZD7288 blocks the hyperpolarization-activated current $(\mathrm{I}(\mathrm{h}))$ in retinal rod photoreceptors. Neuropharmacology 39:1284-1291.

Spruston N, Stuart G, Hausser M (1999) Dendritic integration. In: Dendrites (Stuart G, Spruston N, Hausser M, eds), pp 231-270. Oxford: Oxford UP.

Stone TW (1993) Neuropharmacology of quinolinic and kynurenic acids. Pharmacol Rev 45:309-379.

Stuart GJ, Sakmann B (1994) Active propagation of somatic action potentials into neocortical pyramidal cell dendrites. Nature 367:69-72.

Tank DW, Sugimori M, Connor JA, Llinas RR (1988) Spatially resolved calcium dynamics of mammalian Purkinje cells in cerebellar slice. Science 242:773-777.

Thach Jr WT (1967) Somatosensory receptive fields of single units in cat cerebellar cortex. J Neurophysiol 30:675-696.

Westenbroek RE, Ahlijanian MK, Catterall WA (1990) Clustering of $\mathrm{L}$-type $\mathrm{Ca}^{2+}$ channels at the base of major dendrites in hippocampal pyramidal neurons. Nature 347:281-284.

Westenbroek RE, Hell JW, Warner C, Dubel SJ, Snutch TP, Catterall WA (1992) Biochemical properties and subcellular distribution of an N-type calcium channel alpha 1 subunit. Neuron 9:1099-1115.

Williams SR, Christensen SR, Stuart GJ, Hausser M (2002) Membrane potential bistability is controlled by the hyperpolarization-activated current $\mathrm{I}(\mathrm{H})$ in rat cerebellar Purkinje neurons in vitro. J Physiol (Lond) 539:469-483.

Xia Y, Haddad GG (1994) Postnatal development of voltage-sensitive $\mathrm{Na}^{+}$channels in rat brain. J Comp Neurol 345:279-287.

Yoon KW, Covey DF, Rothman SM (1993) Multiple mechanisms of picrotoxin block of GABA-induced currents in rat hippocampal neurons. J Physiol (Lond) 464:423-439. 